\title{
Erratum: Therapeutic effect of a novel anti-parkinsonian agent zonisamide against MPTP (1-methyl-4-phenyl-1,2,3,6- tetrahydropyridine) neurotoxicity in mice
}

\author{
Hironori Yokoyama $\cdot$ Ryohei Yano $\cdot$ Hayato Kuroiwa • \\ Tatsuya Tsukada • Hiroto Uchida • Hiroyuki Kato • \\ Jiro Kasahara • Tsutomu Araki
}

Published online: 12 January 2011

(C) Springer Science+Business Media, LLC 2011

\section{Erratum to: Metab Brain Dis (2010) 25:305-313 DOI 10.1007/s11011-010-9212-z}

Due to a problem in the production process this article was published twice as DOI 10.1007/s11011-010-9191-0 in Metab Brain Dis (2010) 25:135-143 and as DOI 10.1007/ s11011-010-9212-z in Metab Brain Dis (2010) 25:305-313.

Springer apologizes for any confusion caused by the duplicate publication.

\footnotetext{
T. Araki: Deceased

The online version of the original article can be found at http://dx.doi. org/10.1007/s11011-010-9212-z.

H. Yokoyama $\cdot$ R. Yano $\cdot$ H. Kuroiwa $\cdot$ T. Tsukada $\cdot$ H. Uchida $\cdot$

J. Kasahara $(\triangle) \cdot$ T. Araki

Department of Neurobiology and Therapeutics,

Institute of Health Bioscience,

Graduate School and Faculty of Pharmaceutical Sciences,

The University of Tokushima,

1-78, Sho-machi,

Tokushima 770-8505, Japan

e-mail: awajiro@ph.tokushima-u.ac.jp

H. Kato

Department of Neurology, Organized Center of Clinical Medicine, International University of Health and Welfare Hospital,

Tochigi, Japan
} 